\title{
Molecular dynamic simulations of Escherichia coli L-asparaginase to illuminate its role in deamination of asparagine and glutamine residues
}

\author{
Rajeswara Reddy Erva ${ }^{1}\left(\mathbb{D} \cdot\right.$ Satish Babu Rajulapati ${ }^{1} \cdot$ Chandrasai Potla Durthi $^{2} \cdot$ \\ Mayuri Bhatia ${ }^{1} \cdot$ Madhuri Pola $^{1}$
}

Received: 10 June 2015/ Accepted: 7 July 2015/Published online: 29 December 2015

(C) The Author(s) 2015. This article is published with open access at Springerlink.com

\begin{abstract}
Acute lymphocytic leukemia (ALL) is an outrageous disease worldwide. L-Asparagine (L-Asn) and LGlutamine (L-Gln) deamination play a crucial role in ALL treatment. Role of Elspar ${ }^{\circledR}$ (L-asparaginase from Escherichia coli) in regulation of L-Asn and L-Gln has been confirmed by the other researchers through experimental studies. Therapeutic research against ALL remained elusive with the lack of information on molecular interactions of Elspar ${ }^{\circledR}$ with amino acid substrates. In the present study, using different docking tools binding cavities, key residues in binding and ligand binding mechanisms were identified. For the apo state enzyme and ligand bound state complexes, MD simulations were performed. Trajectory analysis for $30 \mathrm{~ns}$ run confirmed the kinship of L-Asn with Lasparaginase enzyme in the dynamic system with less stability in comparison to L-Gln docked complex. Overall findings strongly supported the bi-functional nature of the enzyme drug. A good number of conformational changes were observed with 1NNS structure due to ligand binding. Results of present study give much more information on structural and functional aspects of $E$. coli L-asparaginase upon the interaction with its ligands which may be useful in designing effective therapeutics for ALL.
\end{abstract}

Electronic supplementary material The online version of this article (doi:10.1007/s13205-015-0339-9) contains supplementary material, which is available to authorized users.

Rajeswara Reddy Erva

rajeshreddy.bio@gmail.com

1 Department of Biotechnology, National Institute of Technology Warangal, Warangal 506004, Telangana, India

2 School of Information Technology, Jawaharlal Nehru Technological University Hyderabad, Hyderabad 500085, Telangana, India
Keywords L-asparaginase - Molecular docking · Molecular dynamic simulations - Acute lymphocytic leukemia

\section{Introduction}

Uncontrolled division of cells is defined as cancer. Cancer of white blood cells (WBC), characterized by excessive multiplication of malignant and immature WBC (lymphoblast) in bone marrow is referred to as acute lymphoblastic leukemia (ALL). Methods of treatment of acute leukemia include chemotherapy, radiation therapy, steroids, and intensive combined treatments including stem cell or bone marrow transplants. Chemotherapy is the most preferred way of treatment among the above. Various drugs employed for treatment of ALL include asparaginase, dexamethasone, prednisolone, vincristine, daunorubicin, cyclophosphamide, cytarabine, etoposide, thioguanine, mercaptopurine, hydrocortisone, methotrexate etc.

Recently L-asparaginase has evolved as an important enzyme in growing enzyme industry, owing to its potential use in the treatment of ALL and lymphosarcoma (Story et al. 1993; Verma et al. 2007) and also in food industry to prevent acrylamide formation in fried foods at high temperatures (Pedreschi et al. 2008). L-asparaginase catalyzes the hydrolysis of amide group of side chain in L-Asn to yield L-aspartate and ammonia. By treating patients with Lasparaginase, circulating plasma pools L-Asn levels were effectively depleted in the body (Fig. 1), resulting in the inhibition of protein synthesis followed by inhibition of DNA and RNA synthesis. It causes apoptic cell death of leukemic cells, thereby makes it selective against the leukemic cells without affecting the normal cells (Nandy et al. 


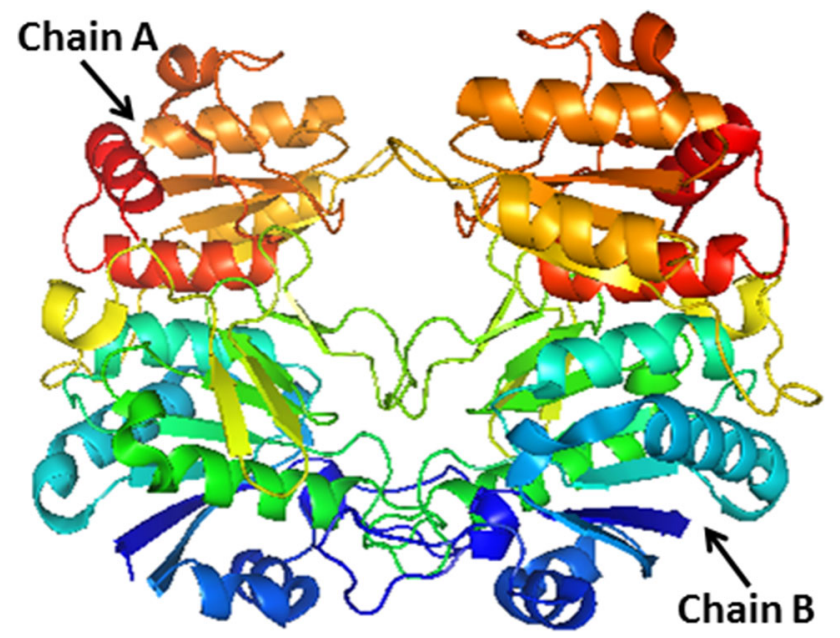

Fig. 1 Crystal structure of E. coli L-asparaginase (PDB ID: 1NNS)

1997). As some leukemic cells are unable to synthesize the asparagine synthetase enzyme, they are totally dependent on circulating extracellular L-Asn. Currently L-asparaginase purified from Escherichia coli is extensively used in clinical treatment of leukemia which is available in the market with the brand name of Elspar ${ }^{\circledR}$ (PDB ID: 1NNS). The possible side effects reported with Elspar ${ }^{\circledR}$ include severe allergic reactions (rash; hives; itching; difficulty breathing; tightness in the chest; swelling of the mouth, face, lips, or tongue); fever; pain, redness, or swelling at the injection site; symptoms of liver problems (e.g., dark urine, pale stools, nausea, loss of appetite, unusual tiredness, yellowing of the skin, or eyes); symptoms of pancreatitis (e.g., severe stomach or back pain with or without nausea or vomiting); neurological seizures and induction of anti-asparaginase antibodies that inactivate the anti-cancer enzyme (Verma et al. 2007; Heinemann and Howard 1969; Savitri and Azmi 2003). To overcome the toxicity associated with preparations of asparaginase from the current sources, there is a need for identification of a new serologically different enzyme which has the same therapeutic effect. To obtain a better and alternative source of L-asparaginase, there is a huge ongoing interest to screen various organisms from various biodiversities.

Although the L-asparaginase enzyme from guinea pig serum has no L-Glutaminase activity (Tower et al. 1963), bacterial L-asparaginase exhibits its activity with L-Gln as a substrate (Campbell and Mashburn 1969; Campbell et al. 1967; Howard and Carpenter 1972; Roberts et al. 1972; Tosa et al. 1972; Wriston Jr 1971). These two activities have been studied in E. coli enzyme preparations (Campbell and Mashburn 1969; Miller and Balis 1969). Upon treating patients of ALL with L-asparaginase, a marked depletion in both extracellular and intracellular glutamine has been observed both in vitro (Bussolati et al. 1995;
Uggeri et al. 1995) and in vivo (Ollenschläger et al. 1988; Reinert et al. 2006; Rudman et al. 1971). In many tissues, a severe metabolic stress is caused by Glutamine starvation and is followed by the up-regulation of the expression and/ or activity of glutamine synthetase (GS) that obtains glutamine from glutamate and ammonium (Lacoste et al. 1982). Treatment with the anti-tumor enzyme produces a marked increase in GS expression and a stimulation of GS activity. Moreover, in the same cells the inhibition of GS activity abolishes resistance to the cytotoxic effects of asparaginase leading to massive cell death. In those cells that are poorly sensitive to the anti-tumor enzyme, the effects of asparaginase are significantly enhanced by GS inhibition (Tardito et al. 2007). This laid the platform for this current study to understand the molecular information about the enzyme and its interactions with the substrates through docking and testing the stability of the enzyme and docked complexes under physiological conditions by molecular dynamics and simulations methods.

\section{Materials and methods}

\section{Preparation of ligands and receptor}

Ligand molecules L-Asn $\left(\mathrm{C}_{4} \mathrm{H}_{8} \mathrm{~N}_{2} \mathrm{O}_{3}\right)$ and L-Gln $\left(\mathrm{C}_{5} \mathrm{H}_{10} \mathrm{~N}_{2} \mathrm{O}_{3}\right)$ whose molecular masses are 132.12 and $146.14 \mathrm{~g} / \mathrm{mol}$ were retrieved from Zinc database with ID numbers 1532556 and 1532526 , respectively. Then they were subjected for energy minimization using the MMFF (Merck Molecular Force Field) (Halgren 1996) of VLifeMDS v 4.3 that works based on MM3 force fields until reaching global minima. Crystal structure of L-asparaginase II from E. coli was obtained from Protein Data Bank (PDB: 1NNS) (Sanches et al. 2003).

\section{Molecular docking using Hex 8.0.0, PatchDock and FireDock}

Hex is a rigid-body docking tool for use with large molecules such as DNA and proteins. Assuming the ligand is rigid, it computes protein ligand docking using Spherical Polar Fourier (SPF) correlations to accumulate the calculations (Sridhar et al. 2005). Global docking score can be obtained as a function of the six degrees of freedom in rigid-body docking, by scripting expressions for the overlay of pairs of parametric functions (Ritchie 2003; Ritchie and Kemp 2000). The docking score was obtained using the default parameters, and the same was interpreted as interaction energy between the ligand and receptor.

In order to verify the results obtained by Hex, another molecular docking was performed by Patch Dock server by submitting the structures to web server (Schneidman- 
Duhovny et al. 2005) that works based on shape complementarity principles and again the outcomes were refined with FireDock server (Andrusier et al. 2007; Mashiach et al. 2008) that reshuffles the interface side chains and amends the molecule's relative orientation. Analysis of ligand binding interactions and docking viability was done based on Fire Dock scores and visualized using Pymol.

\section{Molecular dynamics and simulations}

MD simulations were executed for the apo enzyme, 1NNS-L-Asn (complex 1) and 1NNS-L-Gln (complex 2) docked complexes gained from molecular docking to ratify the stability for anti-cancer enzyme in apo state and bound state with the substrates in dynamic system. Generating both the L-Asn and L-Gin topologies using PRODRG server is the early step in MD simulations (Schüttelkopf and Van Aalten 2004). After defining ligand topologies, MD simulation for apo enzyme and docked complexes was carried

Table 1 Molecular docking results of 1NNS with ligand substrates

\begin{tabular}{lllll}
\hline S. No. & Ligand & Residue: atom & Ligand atom & $\begin{array}{l}\text { Bond length } \\
(\AA)\end{array}$ \\
\hline 1 & L-Asparagine & ILE182: $\mathrm{O}$ & $\mathrm{N}_{1}$ & 2.6 \\
& & ASN184: $\mathrm{N}$ & $\mathrm{O}_{3}$ & 2.8 \\
2 & L-Glutamine & ARG116: $\mathrm{NH}_{2}$ & $\mathrm{O}_{1}$ & 2.8 \\
& & ARG116: $\mathrm{NE}$ & $\mathrm{O}_{1}$ & 2.2 \\
& & SER120: $\mathrm{OG}$ & $\mathrm{N}_{2}$ & 2.6 \\
& & SER120: $\mathrm{OG}$ & $\mathrm{O}_{2}$ & 2.3 \\
& & ASP152: $\mathrm{OD}_{2}$ & $\mathrm{~N}_{1}$ & 2.5 \\
\hline
\end{tabular}

Table 2 A summary of molecular docking results

\begin{tabular}{lll}
\hline Docking tool & \multicolumn{2}{l}{ Ligand } \\
\cline { 2 - 3 } & L-Asparagine & L-Glutamine \\
\hline Hex 8.0 & $-160.89 \mathrm{~kJ} / \mathrm{mol}$ & $-165.60 \mathrm{~kJ} / \mathrm{mol}$ \\
PatchDock and FireDock & $-22.72 \mathrm{kcal} / \mathrm{mol}$ & $-21.46 \mathrm{kcal} / \mathrm{mol}$ \\
\hline
\end{tabular}

using GROMACS 4.6.5 program package under Ubuntu 14.04 operating system. Steepest algorithm using the OPLS force field (Lindahl et al. 2001) was used for energy minimization, dismissing the step when the maximum force is found lesser than $1000 \mathrm{~kJ} \mathrm{~mol}^{-1} \mathrm{~nm}^{-1}$. To provide an aqueous environment in a system of a cubic box with a size of $1.0 \mathrm{~nm}$ and at least $2.0 \mathrm{~nm}$ between any two periodic protein images, all the molecules were solvated. With the addition of six Sodium ions, the system was neutralized and periodic boundary conditions were applied in all directions. The cubic interpolation order in Particle Mesh Ewald (PME) simulation method is 4 and the grid spacing for FFT (Fourier spacing) is 0.16 . In the neighbor searching method, the short-range neighbor list cutoff of $1 \AA$ is taken commonly for electrostatic interactions and van der Waal interactions. The LINCS (Hess et al. 1997) and SETTLE algorithms (Miyamoto and Kollman 1992) were applied to constrain all bond lengths and geometry of water molecules, respectively, in the system. For 100 ps duration, the two equilibration phases, NVT ensemble with a constant temperature of $300 \mathrm{~K}$, coupling constant of $0.1 \mathrm{ps}$, and NPT ensemble with constant pressure of 1 bar, coupling constant of $2 \mathrm{ps,} \mathrm{were} \mathrm{applied} \mathrm{for} \mathrm{all} \mathrm{the} \mathrm{molecules.}$ Modified Berendsen thermostat coupling scheme algorithm was employed for both ensembles of equilibration. Once the system equilibration with constant temperature and pressure is done, a $30 \mathrm{~ns}$ production MD run was performed to carry out the structural and energy analyses. Run trajectories were obtained and quality assurance of all the molecules was done with GROMACS utilities, namely g_energy, g_rms, g_rmsf and g_gyrate. Hydrogen bonding analysis was done by g_hbond. Using XMGRACE tool, the entire trajectory results were analyzed (Turner 2005).

\section{Results and discussion}

As per the structural description provided by the depositors a total of nine $\alpha$-helices $(54-59 ; 85-98 ; 114-124 ; 147-159$; $248-255 ; 273-284 ; 308-311 ; 321-331$ and $338-345)$ and
Fig. 2 Molecular Docking results of 1 NNS with ligand substrates. a Binding with Lasparagine. b Binding with Lglutamine
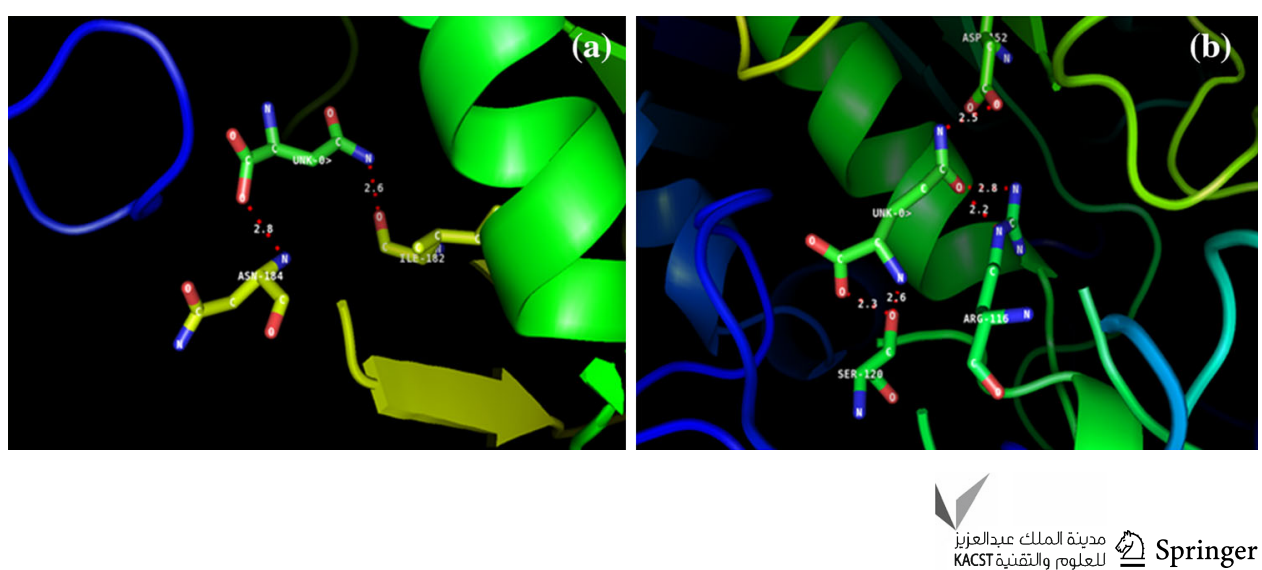
fourteen $\beta$-sheets $\quad(25-32 ; \quad 69-78 ; \quad 104-108 ; 131-134$; $169-172$; 175-178; 182-184; 193-195; 202-205; 208-211; 236-240; 260-265; 288-293 and 313-315) are present in it. Based on interpro analysis (http://www.ebi.ac.uk/ interpro/), N-terminus of 1NNS has two conserved threonine residues with catalytic role.

\section{Docking with L-asparagine and L-glutamine}

Two ligand substrates namely L-Asn and L-Gln were docked into the catalytic site of 1NNS. Dock runs of ligands on the enzyme were performed using HEX 8.0.0 and PatchDock.

When docking runs were carried out by HEX 8.0.0, 1NNS showed very high binding affinity (i.e., high $\mathrm{E}$ total value) with L-Asn and L-Gln resulting in less free energy of -160.89 and $-165.60 \mathrm{~kJ} / \mathrm{mol}$, respectively. Results obtained by HEX were validated by PatchDock webserver followed by refinement of obtained results with FireDock server. Outcomes strongly supported the previous results with a very good binding efficiency between receptor and ligands with the calculated global energy values of -22.72 and $-21.46 \mathrm{kcal} / \mathrm{mol}$ for $\mathrm{L}-\mathrm{Asn}$ and $\mathrm{L}-\mathrm{Gln}$, respectively, (this value is considered to be related to free binding energy) by FireDock server. Enzyme made inter molecular hydrogen bonds (shown in red color) with ILE-182, ASN184 with L-Asn ligand and on the other side generated same inter molecular hydrogen bonds with ARG-116, SER-120, and ASP-152 when L-Gln as the ligand (Table 1). A summary of the binding energies by all the docking methods is described in Table 2. The mode of binding and cavity of ligands with receptor was investigated in PyMol molecular graphics viewer (Fig. 2). Crosschecking of the 1NNS binding sites in docking was done with active site prediction tool FT Site (Ngan et al. 2012; Brenke et al. 2009). The pooled results exhibited matching of most of the residues and thus the binding sites used in docking approach were well-defined (Refer to Online Resource 1). Present investigation results reveal that the nearly equal affinity of Elspar ${ }^{\circledR}$ toward both the ligands strongly supports the asparaginase and glutaminase activities of the enzyme (Keating et al. 1993; Derst et al. 2000). Numerous adverse effects of L-asparaginase usage have also been stated, distant from severe immunogenic reactions (Kwon et al. 2009).

\section{Molecular dynamics and simulations in water}

To check the structural behavior of apo enzyme and docked complexes in the dynamic system, MD simulations were performed and the trajectory analysis was done using
GROMACS utilities. The total energy found from g_energy results for apo enzyme, complex 1 and complex 2 was found to be $-1,652,980, \quad-1,805,840$, and $-1,806,110 \mathrm{~kJ} / \mathrm{mol}$, respectively, demonstrating that the models were energetically firm (Fig. 3). The structural convergence comprises terms like Root Mean Square Deviation (RMSD), Root Mean Square Fluctuation (RMSF), and Radius of Gyration $(R g)$. The g_rms based results with backbone atoms (Fig. 4) exhibited initial equilibration up to $5.5 \mathrm{~ns}$ and the structure underway to converge later and achieved stability with a RMSD between 0.2 and $0.5 \mathrm{~nm}$ with a peak after $26 \mathrm{~ns}$ for $1 \mathrm{NNS}$ in apo state, whereas the docked complex 1 attained equilibration at $10 \mathrm{~ns}$. After the initial equilibration, it was stable throughout the trajectory oscillating between RMSD

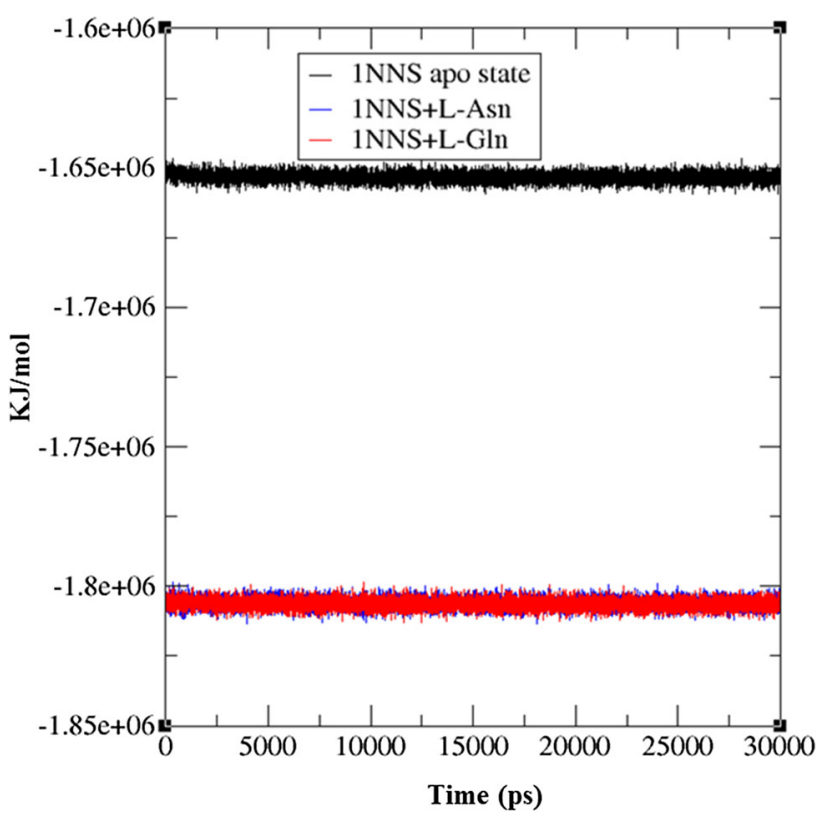

Fig. 3 Total energy of apo state 1NNS and its docked complexes

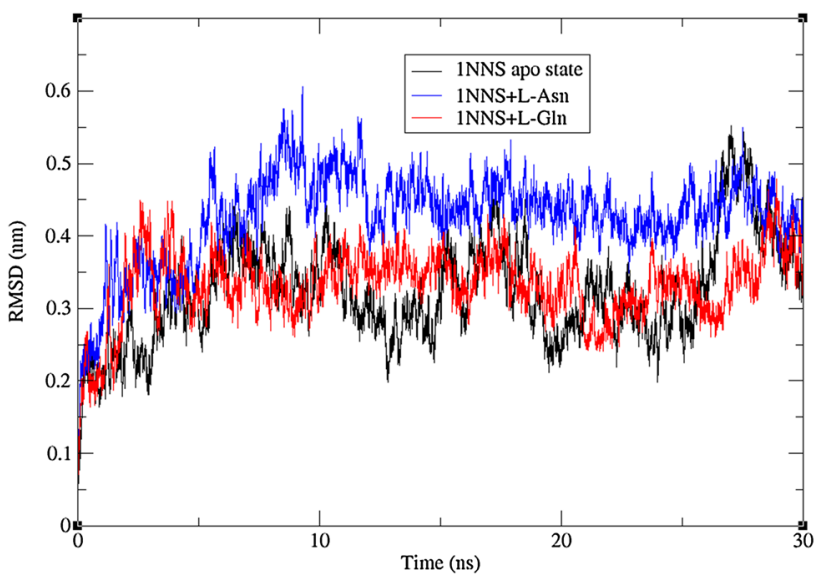

Fig. 4 RMSD plots of backbone atoms during 30 ns simulations 
Fig. 5 RMSF of $\mathrm{C} \alpha$ atoms along with RMSF of $\mathrm{C} \alpha$ atoms a 1 NNS apo enzyme and $1 \mathrm{NNS}+\mathrm{L}$-Asn. b 1NNS apo enzyme and $1 \mathrm{NNS}+\mathrm{L}-\mathrm{Gln}$
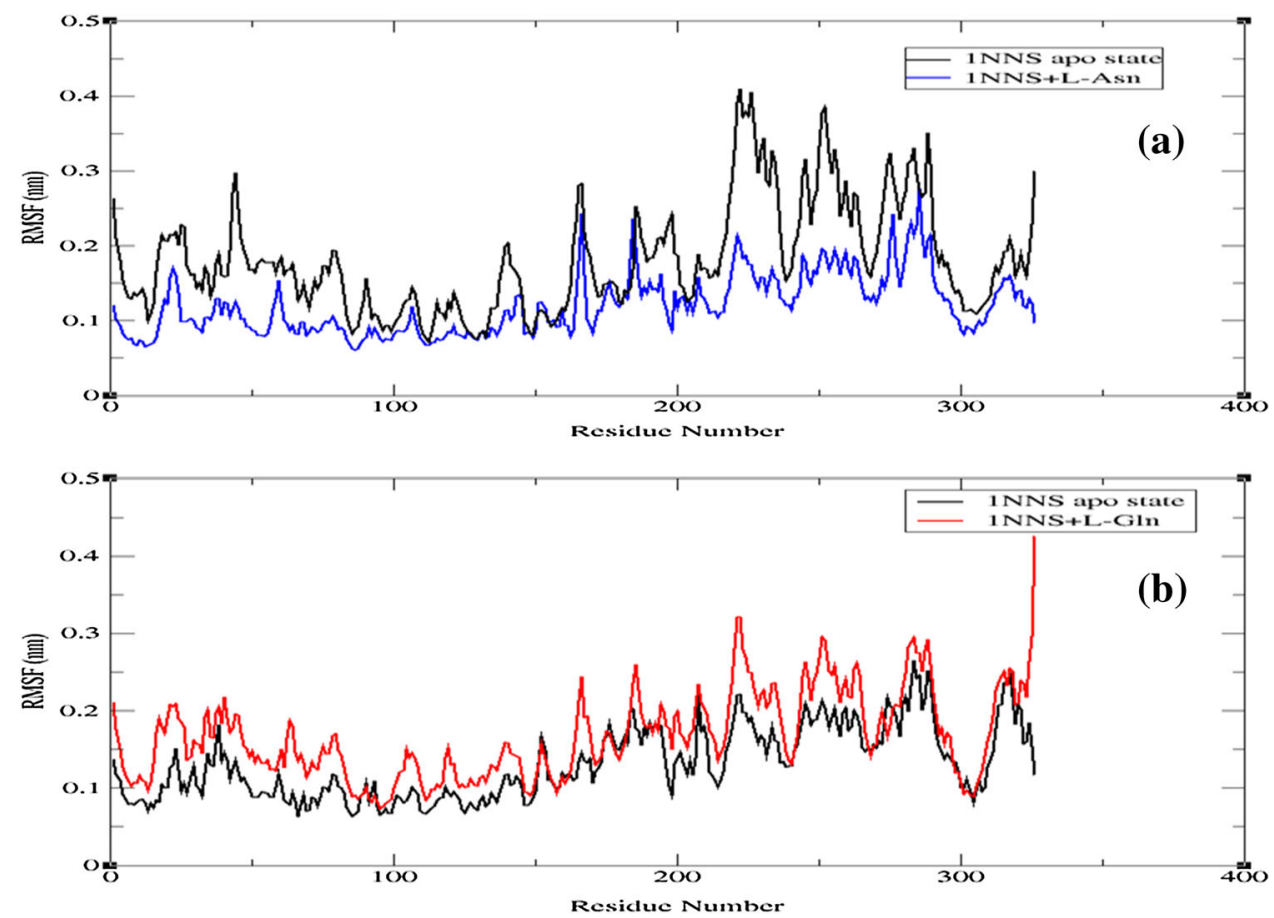

Table 3 Comparison of RMSF values from MD simulations

\begin{tabular}{lllll}
\hline S. no. & Residue & \multicolumn{2}{l}{ RMSF $(\mathrm{nm})$} & \\
\cline { 3 - 5 } & & 1NNS in apo state & Complex 1 & Complex 2 \\
\hline 1 & ARG116 & 0.0875 & - & 0.1016 \\
2 & SER120 & 0.0902 & - & 0.1305 \\
3 & ASP152 & 0.1667 & - & 0.1568 \\
4 & ILE182 & 0.1372 & 0.1295 & - \\
5 & ASN184 & 0.1684 & 0.2356 & - \\
\hline
\end{tabular}

values of 0.4 and $0.5 \mathrm{~nm}$ which were a little higher than apo state enzyme. Although complex 2 initially followed apo state enzyme, it achieved a stable conformation throughout the simulation soon after the first 4 ns with an average backbone RMSD between 0.26 and $0.42 \mathrm{~nm}$. By showing much higher consistency throughout the entire trajectory, docked complex 2 confirmed its stable conformation over both the apo state enzyme and complex 1 . The examination of g_rmsf results presented the oscillations with $\mathrm{C} \alpha$ atoms with respect to residues. Results of g-rmsf analysis revealed a few fluxes in $\mathrm{C} \alpha$ atoms with respect to apo enzyme residues. As per RMSF plot residues of complex 1 are stable (Fig. 5a) with a few peaks with RMSF value of more than $0.25 \mathrm{~nm}$ compared to complex 2 (Fig. 5b) where many residues are oscillating around $0.3 \mathrm{~nm}$ along with one high peak at the last one with $0.4 \mathrm{~nm}$. The comparison of RMSF outcomes showed minor variations in ligand binding sites (Table 3 ) and their effect on complex formation. Radius of gyration $\left(R_{\mathrm{g}}\right)$ describes

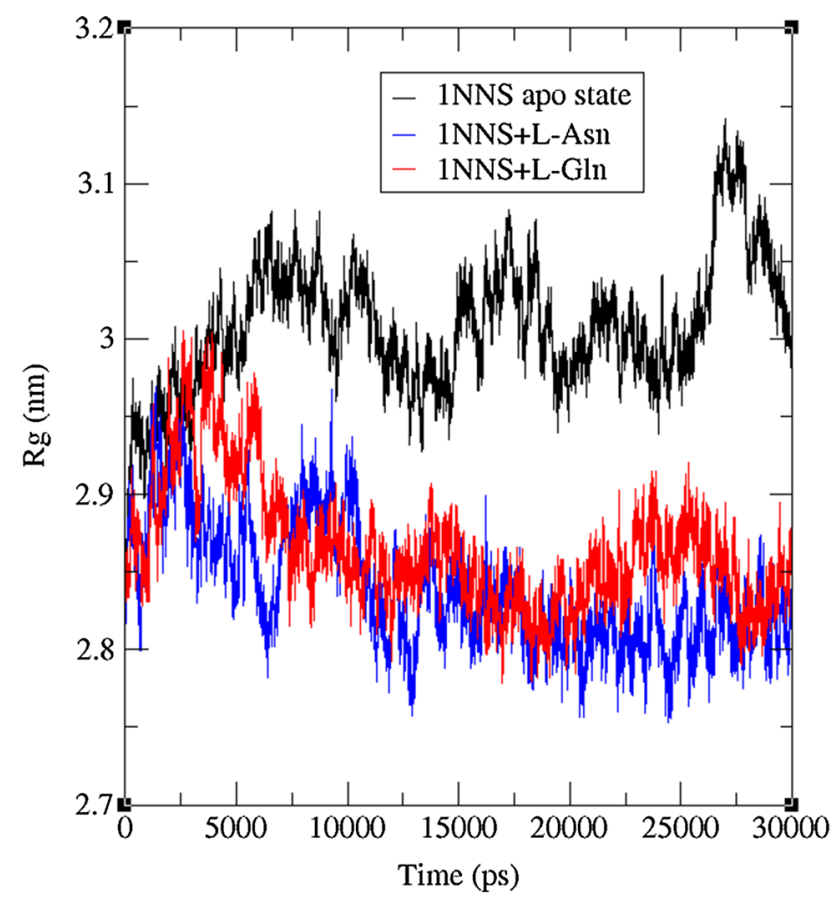

Fig. 6 Radius of gyration plot during 30 ns simulations

overall spread of molecule and was calculated using g_gyrate tool of GROMACS. Continuous drifts in gyration radii for apo state enzyme in the range of nearly 2.9 and $3.15 \mathrm{~nm}$ describe the dynamic nature of 1NNS. Docked complexes are better in terms of conformational stability with constant and low $R_{\mathrm{g}}$ values authorizing their better folding (Fig. 6) than unbound enzyme. Complex 1 was 

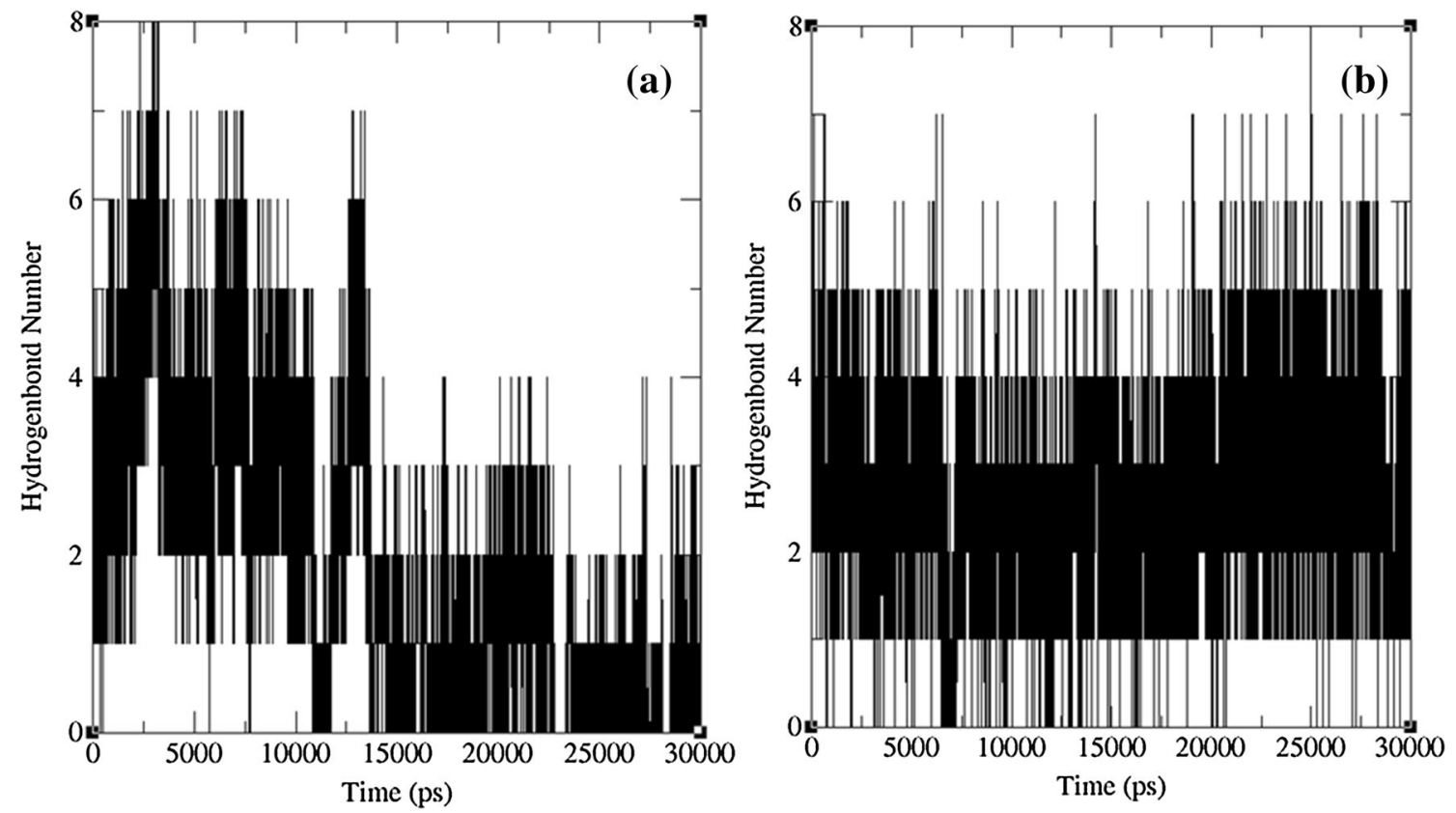

Fig. 7 Inter-hydrogen bonding for docked complexes

stable during entire MD run after 13 ns with no further drifts till end, and the second complex was stable only after $6 \mathrm{~ns}$. The hydrogen bonding interactions between the docked complexes confirmed the hydrogen bonding pattern throughout $30 \mathrm{~ns}$ simulations (Fig. 7). Inter-hydrogen bond interactions pattern was clearly explained by the binding of L-Asn (Fig. 7a) and L-Gln (Fig. 7b) in the apo state initially with more number of hydrogen bonds which were reduced to 2-3 after the change in conformation due to binding after $12 \mathrm{~ns}$ simulations. Although MD simulation results were well correlated with molecular docking results with two to five hydrogen bonds seen in the dynamic state, surprisingly loss of hydrogen bonds at the end of simulations for complex 1 was observed. Overall, hydrogen bonding interactions revealed the affinity of ligand molecules with $E$. coli L-asparaginase and its dual activity. An overall result from this computational study confirms the dual functionality of the E. coli L-asparaginase enzyme. The instability of the enzyme upon the interaction with the ligand substrates based on RMSD, RMSF, and H-bond analysis suggests the need for identifying a new and stable L-asparaginase enzyme from diverse source with similar therapeutic effects for better curing of ALL.

\section{Conclusion}

L-asparaginase is one of the most attractive enzymes in cancer research. Investigational studies on E. coli sustained it as one of the therapeutic agents for ALL. In the present computational study, ligand binding pattern on 1NNS with
L-Asn and L-Gln using molecular docking explained the binding mechanism at molecular level. Binding cavities and the key residues in binding were identified based on the docking results. MD simulations of complex 1 for $30 \mathrm{~ns}$ run confirmed the kinship of L-Asn in the dynamic system with less stability than complex 2 . Overall findings strongly supported the bi-functional nature of the enzyme drug. Many conformational changes were observed with 1NNS structure due to the ligand binding. Results of this in silico studies favor added extensive structural research on L-asparaginase toward scheming of potential inhibitors that can be used in effective treatment of ALL.

Acknowledgments Authors would like to thank Director, National Institute of Technology Warangal, Warangal, India, for the kind support in bringing out the above literature and providing lab facilities.

\section{Compliance with ethical standards}

Conflict of interest Authors have no conflict of interest regarding the publication of paper.

Open Access This article is distributed under the terms of the Creative Commons Attribution 4.0 International License (http:// creativecommons.org/licenses/by/4.0/), which permits unrestricted use, distribution, and reproduction in any medium, provided you give appropriate credit to the original author(s) and the source, provide a link to the Creative Commons license, and indicate if changes were made.

\section{References}

Andrusier N, Nussinov R, Wolfson HJ (2007) FireDock: fast interaction refinement in molecular docking. Proteins Struct Funct Bioinform 69:139-159 
Brenke R et al (2009) Fragment-based identification of druggable 'hot spots' of proteins using Fourier domain correlation techniques. Bioinformatics 25:621-627

Bussolati O, Belletti S, Uggeri J, Gatti R, Orlandini G, Dall'Asta V, Gazzola GC (1995) Characterization of apoptotic phenomena induced by treatment with L-asparaginase in NIH3T3 cells. Exp Cell Res 220:283-291

Campbell HA, Mashburn LT (1969) L-Asparaginase EC-2 from Escherichia coli. Some substrate specificity characteristics. Biochemistry 8:3768-3775

Campbell H, Mashburn L, Boyse E, Old L (1967) Two L-asparaginases from Escherichia coli B. Their Separation, Purification, and Antitumor Activity*. Biochemistry 6:721-730

Derst C, Henseling J, Röhm KH (2000) Engineering the substrate specificity of Escherichia coli asparaginase II. Selective reduction of glutaminase activity by amino acid replacements at position 248. Protein Sci 9:2009-2017

Halgren TA (1996) Merck molecular force field. I. Basis, form, scope, parameterization, and performance of MMFF94. J Comput Chem 17:490-519

Heinemann B, Howard AJ (1969) Production of tumor-inhibitory Lasparaginase by submerged growth of Serratia marcescens. Appl Microbiol 18:550-554

Hess B, Bekker H, Berendsen HJ, Fraaije JG (1997) LINCS: a linear constraint solver for molecular simulations. J Comput Chem 18:1463-1472

Howard JB, Carpenter FH (1972) L-Asparaginase from Erwinia carotovora substrate specificity and enzymatic properties. J Biol Chem 247:1020-1030

Keating MJ, Holmes R, Lerner S, Ho DH (1993) L-Asparaginase and PEG asparaginase-past, present, and future. Leuk Lymphoma 10:153-157. doi:10.3109/10428199309149129

Kwon YM et al (2009) L-Asparaginase encapsulated intact erythrocytes for treatment of acute lymphoblastic leukemia (ALL). J Controlled Release 139:182-189

Lacoste L, Chaudhary KD, Lapointe J (1982) Derepression of the glutamine synthetase in neuroblastoma cells at low concentrations of glutamine. J Neurochem 39:78-85

Lindahl E, Hess B, Van Der Spoel D (2001) GROMACS 3.0: a package for molecular simulation and trajectory analysis. Mol Model Ann 7:306-317

Mashiach E, Schneidman-Duhovny D, Andrusier N, Nussinov R, Wolfson HJ (2008) FireDock: a web server for fast interaction refinement in molecular docking. Nucleic Acids Res 36:W229_ W232. doi:10.1093/nar/gkn186

Miller HK, Balis ME (1969) Glutaminase activity of L-asparagine amidohydrolase. Biochem Pharmacol 18:2225-2232

Miyamoto S, Kollman PA (1992) SETTLE: an analytical version of the SHAKE and RATTLE algorithm for rigid water models. J Comput Chem 13:952-962

Nandy P, Periclou A, Avramis V (1997) The synergism of 6-mercaptopurine plus cytosine arabinoside followed by PEG-asparaginase in human leukemia cell lines (CCRF/CEM/0 and (CCRF/ $\mathrm{CEM} / \mathrm{ara}-\mathrm{C} / 7 \mathrm{~A}$ ) is due to increased cellular apoptosis. Anticancer Res 18:727-737

Ngan C-H, Hall DR, Zerbe B, Grove LE, Kozakov D, Vajda S (2012) FTSite: high accuracy detection of ligand binding sites on unbound protein structures. Bioinformatics 28:286-287

Ollenschläger G, Roth E, Linkesch W, Jansen S, Simmel A, Mödder B (1988) Asparaginase-induced derangements of glutamine metabolism: the pathogenetic basis for some drug-related sideeffects. Eur J Clin Invest 18:512-516
Pedreschi F, Kaack K, Granby K (2008) The effect of asparaginase on acrylamide formation in French fries. Food Chem 109:386-392

Reinert RB et al (2006) Role of glutamine depletion in directing tissue-specific nutrient stress responses to L-asparaginase. J Biol Chem 281:31222-31233

Ritchie DW (2003) Evaluation of protein docking predictions using Hex 3.1 in CAPRI rounds 1 and 2. Proteins Struct Funct Bioinform 52:98-106

Ritchie DW, Kemp GJ (2000) Protein docking using spherical polar Fourier correlations. Proteins Struct Funct Bioinform 39:178-194

Roberts J, Holcenberg JS, Dolowy WC (1972) Isolation, crystallization, and properties of Achromobacteraceae glutaminase-asparaginase with antitumor activity. J Biol Chem 247:84-90

Rudman D, Vogler WR, Howard CH, Gerron GG (1971) Observations on the plasma amino acids of patients with acute leukemia. Cancer Res 31:1159-1165

Sanches M, Barbosa JARG, De Oliveira RT, Abrahão Neto J, Polikarpov I (2003) Structural comparison of Escherichia coli Lasparaginase in two monoclinic space groups. Acta Crystallogr Sect D 59:416-422. doi:10.1107/S0907444902021200

Savitri NA, Azmi W (2003) Microbial L-asparaginase: a potent antitumour enzyme Indian. J Biotechnol 2:184-194

Schneidman-Duhovny D, Inbar Y, Nussinov R, Wolfson H (2005) Nucleic Acids Res 33 (Web Server issue), W363-367

Schüttelkopf AW, Van Aalten DMF (2004) PRODRG: a tool for high-throughput crystallography of protein-ligand complexes. Acta Crystallogr Sect D 60:1355-1363. doi:10.1107/ S0907444904011679

Sridhar G, Nirmala G, Apparao A, Madhavi A, Sreelatha S, Rani JS, Vijayalakshmi P (2005) Serum butyrylcholinesterase in type 2 diabetes mellitus: a biochemical and bioinformatics approach. Lipids Health Dis 4:18

Story MD, Voehringer DW, Stephens LC, Meyn RE (1993) Lasparaginase kills lymphoma cells by apoptosis. Cancer Chemother Pharmacol 32:129-133

Tardito S et al (2007) The inhibition of glutamine synthetase sensitizes human sarcoma cells to L-asparaginase. Cancer Chemother Pharmacol 60:751-758

Tosa T, Sano R, Yamamoto K, Nakamura M, Chibata I (1972) LAsparaginase form Proteus vulgaris. Purification, crystallization, and enzymic properties. Biochemistry 11:217-222

Tower DB, Peters EL, Curtis WC (1963) Guinea Pig Serum LAsparaginase properties, purification, and application to determination of asparagine in biological samples. J Biol Chem 238:983-993

Turner P (2005) XMGRACE, Version 5.1. 19 Center for Coastal and Land-Margin Research, Oregon Graduate Institute of Science and Technology, Beaverton, OR

Uggeri J, Belletti S, Bussolati O, Dallasta V, Gazzola GC (1995) Suppression of anionic amino acid transport impairs the maintenance of intracellular glutamate in Ha-ras-expressing cells. Biochem Biophys Res Commun 211:878-884

Verma N, Kumar K, Kaur G, Anand S (2007) L-asparaginase: a promising chemotherapeutic agent. Crit Rev Biotechnol 27:45-62

Wriston JC Jr (1971) 5 L-Asparaginase. In: Paul DB (ed) The Enzymes, vol 4. Academic Press, pp 101-121. doi:10.1016/ S1874-6047(08)60365-0 